\title{
The Quest for Quality in Universities
}

\author{
Lewis Evans
}

$\mathrm{Q}$

UALITY is determined by the operation of an organisation as a whole. Industrial organisation literature suggests that the quality and quantity of outputs are jointly determined by pricing, incentives and institutional structure. This is because performance is largely shaped by the incentives and monitoring processes established by the institutional structure of an organisation, of which governance and the allocation of managerial responsibility are of paramount importance.

Successful organisations have incentive structures which direct the actions of employees, delegate decision-making to those individuals with the information and incentives to make good decisions, and establish clear lines of responsibility and accountability between principals and agents at different levels of the organisation. The external incentives facing these organisations determine their objectives and heavily influence internal governance and management arrangements.

In this article it is argued that the current incentives facing universities are inappropriate to the delivery of quality and quantity in teaching and research, but that modern organisational theory and practice may be applied to tertiary educational organisations as a means of resolving these problems.

\section{The Distinctive Features of Universities}

Universities have distinctive features that must be considered in the design of their governance structures and funding arrangements. The Hawke Report (Hawke et al., 1988), many of whose recommendations were incorporated in New Zealand's Education Act 1989, suggests that there are five such features: universities are concerned with 'more advanced learning' and this requires intellectual independence; their teaching and research are interdependent; they are international in stance; they are a repository of knowledge and expertise; and they exercise the function of critic and conscience of society. Together, these factors are said to set universities apart from other educational institutions.

\footnotetext{
'Modern organisational theory is taken to be that of Paul Milgrom and John Roberts (1992). Quality is a complex issue that touches most aspects of an organisation; many relevant topics are not mentioned here, such as the questions of ownership and sources of funds.
}

Lewis Evans is Professor of Economics at Victoria University of Wellington. This is a revised version of paper delivered to the AIC Conference on Tertiary Education in New Zealand, Wellington, 28 May 1997. 
Remarkably, the list does not include the difficulty of tangibly quantifying the outputs of universities. Yet many commentators would regard this characteristic as a key determinant of the appropriate governance and organisational structures because it affects the kinds of structures and employment contracts that are appropriate for universities. ${ }^{2}$ Measurement problems make it difficult to judge the service that these institutions deliver. Customers do not really know the quality of the learning experience either before they embark on a program or, in many cases, even at the conclusion. This information problem, which is a feature of health care as well as education, has arguably increased the weight attributed to the opinions of industry professionals, and contributed to the major role that professionals' organisations have played in influencing policy in both these industries. However, the computing and communications advances that facilitate the assembly and comparison of indicators of performance reduce the scope of the information problem.

These distinctive features of universities may be examined in turn.

The pursuit of advanced learning is not peculiar to universities. But the ability to publish the results of research, and to incorporate them in courses regardless of their content, does set universities apart from most (but not all) other institutions. In New Zealand, this academic freedom is enshrined in Section 161 of the Education Act 1989. In practice, it makes the universities much more tolerant of dissent from, and criticism of, current orthodoxies than are other types of organisation.

However, the bounds of academic freedom are controversial. While academic freedom is appropriate for the unfettered dissemination and debate of research results, it should not be regarded as a justification for inhibiting universities from taking action where the performance of individuals in teaching, research and university management does not meet the reasonable standards that a serious university should set. While academic freedom will be specified in a university's charter and has implications for staff employment contracts, it has minimal implications for the choice of a management model.

The joint production of teaching and research may be a distinctive feature of universities, but it has no implications for their governance or management. Many service organisations produce multiple complementary outputs - actuarial services and investment services are combined in life insurance policies, for example - but such joint services raise no distinctive managerial issues.

Even if universities are international in stance through their research networks, this does not set them apart in the way it may once have done, since the costs of communication have declined and its nature has changed. Certainly, this is not a distinguishing feature that would affect governance and organisational structures. Exactly the same point applies to the university's role as a repository of knowledge. Indeed, it is precisely here that universities are most exposed to the hugely changed information and communications technologies. Universities now find themselves in

\footnotetext{
${ }^{2}$ The production of intangible services and the concomitant asymmetric information problems in education are similar to those of the health sector. The latter are discussed by Richard Frank and David Salkever (1994).
} 
a viably contestable market for information services that transcends international boundaries.

The explicit mandate that New Zealand's universities should exercise 'a role as critic and conscience of society' (enshrined in Section 162(4)(a)(v)) of the Education Act 1989) detracts from the objective of producing quality research and teaching. The only basis for recognising such a role for universities is the Education Act's separate mandate that university staff should carry out and publish quality original research. But, at the very most, the role of critic and conscience of society must be secondary to the primary goal of quality research. It may actually inhibit research quality and undermine the values and goals of the university system by legitimising the involvement of university staff in wide-ranging public debate as part of their university employment, whether or not such debate is in the area of their research and even if they have no credible research record. It brings to mind Adam Smith's famous observation that 'regulatory authority is nowhere so dangerous as in the hands of any man who is foolish and presumptuous enough to fancy himself fit to exercise it' (Smith, 1776/1976:478).

As for the measurement problems associated with the output of universities, virtually all service organisations share this feature in varying degrees. Measurements of services are typically crude indicators of outputs. The time spent and distance travelled in a taxi, for example, are measurable, but are very poor indicators of the quality of the taxi service.

In sum, the distinctive features of universities do not inhibit the application of incentives provided under governance and organisational structures to achieve the institution's goals. Universities are not special in this regard. Indeed this is amply demonstrated by the operation of universities in North America and the United Kingdom.

\section{Monitoring vs Incentives}

There is a trade-off in organisational design between the costs of monitoring activities and the costs of incentives that encourage these activities. ${ }^{3}$ It is present for service organisations, although the nature of the trade-off does depend on the extent to which outputs are quantifiable. Both practice and the literature on organisations have addressed ways of providing incentives that encourage quality services. Although intangible outputs cannot be quantified, judgments can be reached about relative performance on the basis of indicators of service provision.

The competition, or tournament, is a low-cost incentive mechanism for ensuring quality when output is difficult to measure. Tournaments are all-pervasive nowadays, both within organisations (including even universities) and between service providers. They occur where two or more agents are carrying out the same tasks and where the agent that is judged superior is awarded a prize. Tournaments,

\footnotetext{
${ }^{3}$ See Milgrom and Roberts (1992:ch. 8).

${ }^{4}$ See Dilip Mookherjee (1990).
} 
or near tournaments arise in many organisational settings. A simple example might be the appointment of a CEO or a deputy CEO from among managers within a company.

Measurable signals about university performance can be informative. Measured quality of inputs can serve as indicators of the quality of a service to customers and funding agencies: for example, a course taught by an academic with a significant publications record in its subject area is likely to be of a higher quality than a similar course taught by an academic with no such record. Such measures of quality of the inputs and the management process form the basis of some university audits. As a tool of quality assurance, audits have their limitations. As they involve subjective judgments, the outcomes depend partly on the identities of the auditors. Even when they are well done, audits indicate actual achievement (perhaps in the light of some benchmark) rather than potential achievement. And benchmarks can become organisational goals that guide decision-making and become substitutes for the pursuit of excellence. Hence, reliance on audits is costly and can detract from organisational performance.

The costs of monitoring can be reduced by the use of incentives to perform. The competitive, or tournament, institutional structure does provide incentives for excellence at a lower cost of monitoring than would otherwise be the case. If excellence in teaching and research — perhaps as judged by good international standards - is the central public interest, as expressed by student demand and any private or public funding, then the universities that succeed in a competitive environment will be those that focus exclusively on this outcome. Blunt incentives and institutional arrangements that detract from this focus will dilute the tournament and reduce the quality of outcomes. If persons who have not demonstrated excellence in research and teaching are promoted for participating in public debate or willingness to serve on university committees, the internal incentives for excellence are diluted.

For competition to be effective, universities need to be independent, standalone institutions that are free to develop their own products, programs and distinctive brands and reputations. Institutional arrangements that impose collective constraints rather than promoting inter-university competition will require additional monitoring (including auditing) because of the reduced focus on customer satisfaction. But even if the universities did operate independently of one another, incentives would remain for them to cooperate on a range of matters, including joint projects.

\section{University Objectives}

The objective of an organisation flows from ownership and the incentives that confront it. Where incentives are weak, the organisation has some scope to choose its own priorities. Freedom to choose objectives affects organisational structures and the mode of management.

In the case of New Zealand's universities, the guiding incentives have been unclear. This has been reflected in the universities' structure and performance. The lack of clarity is reflected in the composition of university councils and the man- 
agement structures. Scope has existed for objectives other than excellence in teaching and research. If the choice of objectives is open, why not appoint a representative council that will, among other things, select objectives?

Following the enactment of the 1989 Education Act, universities have specified their objectives and have been correspondingly audited by the Ministry of Education. But even so, scope remains for choosing objectives, as is revealed by the different objectives of different institutions. Furthermore, the emphasis is on monitoring benchmarks rather than incentives for excellence. The greater the number of objectives, and the greater the scope for choosing among them, the weaker will be the incentives that management and staff face for any specific objective and the poorer will be the performance in any subset of goals.

To illustrate the implications of multiple objectives for universities, Evans and Quigley (1996) posited three explicit or implicit governance models:

1. The vice-chancellor is viewed as an agent of the staff or some subset of the staff such as professors or chairpersons. This suggests that the vice-chancellor should be viewed as akin to the managing partner of a professional partnership such as a law firm; that the governing body represents the staff; and that they in turn lease the physical assets of the university from the owners.

2. The vice-chancellor is viewed as the agent of the owners, and the council is viewed as a board of directors representing these beneficial owners of the institution.

3. The university is owned by a charitable trust, and the role of the members of the council is to serve as trustees to implement the mission of the university. The vice-chancellor is in this case the agent of the trust. The interests of the government and other stakeholders are met solely through the university's need to satisfy its clients if it is to continue to be viable.

Any of these three models, rigorously applied, might provide a sound basis for the organisation of a university. But since the current governance structure of New Zealand's universities attempts to incorporate both models (1) and (2), it does not do justice to either of them; and the practices, decisions and incentives that flow from it are cumbersome, opaque, and unduly centralised. The existing amalgam of models relies on the representative mode of governance and management, partly because the choice of the objectives of the institution as a whole has been open and staff and current students have sought to influence it by representation.

The choice of objectives has influenced the definition of research, not in minor details but to a significant extent and in matters of principle. Conceivably, New Zealand society is satisfied with individual universities determining what constitutes research. But this is unlikely to ensure that such research reaches standards of demonstrably 'international excellence'. Being able to choose 'research' means being able to choose the criteria by which it is evaluated. It is not being suggested that 
New Zealand's universities do not contain some outstanding scholars, but simply that other routes to pecuniary advancement have commonly been justified against other objectives and that this has significantly affected overall university performance.

If the stakeholders in universities desire the delivery of high-quality outputs, these institutions' range of objectives should be limited and defined, and incentives put in place that sharply focus on the chosen services.

\section{Unbundling Research and Teaching}

The incentives for 'international excellence' could be greatly sharpened by splitting public funding into research and teaching components. In order to focus on this issue, the existence of public funding and ownership that facilitates independent operation of universities is taken as given.

Under the current New Zealand system, in which the bulk of university funding is based simply on enrolments (adjusted for differences in subject costs), the choice of what constitutes research and of the weight given to it lies with the university. Since it takes time to build and even to lose a reputation, bundling research and teaching funding creates scope for emphasis on various objectives. While audits can clarify a university's claim to undertake research of international excellence, the university exercises discretion over any incentives for outstanding research achievement. There are incentives for universities to perform well under the Public Good Science fund in that success does bring in some extra revenue, but most funds for university research are provided on the basis of numbers taught.

The purposes of university research are three-fold. It produces research outputs that are openly available for society's use; it facilitates the teaching of research method; and it is a screening mechanism that determines the kinds of people who teach in university courses. None of these purposes for university research detracts from treating the production of research and education as joint products; and, as pointed out by Hawke et al. (1988), joint products are often priced and funded separately rather than bundled as in the New Zealand system. Unbundling would facilitate the specification of the kind of research required of New Zealand universities (although little leeway would be available if international excellence is demonstrably required) and would make it possible to establish strong incentives for its delivery. These incentives would materially restrict universities' abilities to set their own objectives, and would give clearer signals for the encouragement of quality teaching as well as research.

In the United Kingdom, universities have been funded separately for teaching and research over the past ten years, with very significant effects on their internal organisation, employment contracts and performance. Drawing on the UK experience, the scheme would operate by separating universities' present public funds into teaching and research components, and allocating the latter to subject areas of

\footnotetext{
${ }^{5}$ Total institutional funding is provided as a block grant made up of separate grants for teaching and research. On average, approximately 22 per cent of the grant is for research.
} 
each university according to its ranking on a scale of research excellence. The ranking would be determined every four years by a panel of subject experts. In the UK, research of demonstrably international excellence achieves the higher rankings. The prize for high rankings is substantial in that, all else being equal, a department that receives a ranking of 5 can expect to receive four times the research funds of a department that is ranked at level 2 .

The proposal would see research funds allocated over a period of four years to researchers with demonstrated research expertise without tying them to particular lines of inquiry and projects. Public funding of untied research over fixed periods does not now occur in New Zealand except in universities where the incentives for research performance are vague. If public funds are to be used for research, arguably this mode of research delivery would usefully complement existing public funding of research. It would offer sharp, useful competition to the priority- and project-oriented Public Good Science fund.

Any scheme for allocating research funds will have its problems. The administrative costs of the scheme canvassed here should be evaluated in the light of reductions in monitoring or auditing costs and the improved performance that would result. If the UK scheme were adopted in New Zealand, a central issue would be the selection of panels in a country with, particularly in some areas, a small number of demonstrably qualified research judges.

\section{Concluding Comments}

Nothing about the characteristics of universities precludes consideration of the usual trade-off between monitoring and incentives in organisational design. New Zealand's universities have faced vague incentives and this has been reflected in their multiple objectives, operation and performance. Monitoring can be reduced and much sharper incentives provided by funding research competitively and separately. Independent operation and governance in a competitive environment would foster quality universities.

Similar considerations apply to other tertiary educational institutions. Indeed, the UK scheme applies to all such institutions that meet certain criteria, including research-based ones. Splitting funding into research and teaching, and the concomitant competitive allocation, would sort institutions into those with different functions without relying on audits and all that attends them. Under public funding, it may be possible to offer, say, two sorts of contractual arrangements: one for specified kinds of educational services that did not require 'international research excellence' and the other for the research model discussed above. Institutions would choose one of the two arrangements with the certain knowledge that they

\footnotetext{
${ }^{6}$ Note that the theory of tournaments does suggest that the larger the asymmetric information problem, the larger the prize that should optimally accompany the tournament. See Mookherjee (1990). 7

A version of such an arrangement has been under consideration in the UK.
} 
would be evaluated, and their funding determined, against the terms of the arrangement they had chosen.

\section{References}

Evans, L. \& N. Quigley (1996), 'University Governance: Industrial Organisation in the Context of Tertiary Education', Victoria Economic Commentaries 13(1): 23-7.

Frank, R. \& D. Salkever (1994), 'Nonprofit Institutions in the Health Sector', Journal of Economic Perspectives 8(4): 129-44.

Hawke, G. et al. (1988), Report of the Cabinet Social Equity Committee Working Group on Post Compulsory Education and Training, Government Printer, Wellington.

Milgrom, P. \& J. Roberts (1992), Economics, Organisation and Management, Prentice Hall, New Jersey.

Mookherjec, D. (1990), 'Rank Order Competition and Incentives: An Organisational Perspective', pp. 194-229 in D. Bhaskar, S. Gangopadhyay, D. Mookherjee \& D. Ray (eds), Economic Theory and Policy: Essays in Honour of Dipak Banejjee, Oxford University Press, Oxford.

Smith, A. (1776, 1976), An Inquiry into the Nature and Causes of the Wealth of Nations, vol. 1, ed. E. Cannon, University of Chicago Press, Chicago.

This article has benefited from the very helpful comments of two anonymous referees. In deference to one referee, I concede that an explanation for my writing this article is, in terms of its argument, non-optimal incentives of the institution that employs me. I am indebted to Alice Frost, of the Policy Division of the Higher Education Funding Council for England, for information on the UK scheme, and to Neil Quigley for comments. 